\title{
Benzo[a]pyrene impairs the migratory pattern of human gonadotropin-releasing- hormone-secreting neuroblasts
}

\author{
Giulia Guarnieri, ${ }^{1}$ Matteo Becatti, ${ }^{2}$ Paolo Comeglio, ${ }^{2}$ Linda Vignozzi, ${ }^{2}$ Mario Maggi, ${ }^{2}$ Gabriella Barbara Vannelli, \\ Annamaria Morelli ${ }^{1}$ \\ ${ }^{1}$ Department of Experimental and Clinical Medicine; ${ }^{2}$ Department of Experimental and Clinical Biomedical Sciences \\ “Mario Serio", University of Florence, Italy
}

\begin{abstract}
Benzo[a]pyrene $(\mathrm{BaP})$ is a widespread pollutant that can act as an endocrine disrupting compound (EDC) and interferes with reproductive function. The central regulatory network of the reproductive system is mediated by gonadotropin-releasing hormone $(\mathrm{GnRH})$ neurons, which originate in the olfactory placode and, during ontogenesis, migrate into the hypothalamus. Given the importance of the migratory process for GnRH neuron maturation, we investigated the effect of $\mathrm{BaP}(10 \mu \mathrm{M}$ for $24 \mathrm{~h})$ on $\mathrm{GnRH}$ neuroblasts isolated from the human fetal olfactory epithelium (FNCB4). BaP exposure significantly reduced the mRNA level of genes implicated in FNCB4 cell migration and affected their migratory ability. Our findings demonstrate that BaP may interfere with the central neuronal network controlling human reproduction affecting GnRH neuron maturation.
\end{abstract}

Key words: GnRH neurons; benzo[a]pyrene; EDCs; cell migration; reproductive function; pollution; hypogonadotropic hypogonadism.

Correspondence: Prof. Annamaria Morelli, Section of Human Anatomy and Histology, Department of Experimental and Clinical Medicine, University of Florence, L.go Brambilla 3, 50134 Florence, Italy.

Tel. +39.055.2758058. E-mail: a.morelli@unifi.it

Contributions: GG, performed experiments, analyzed data, generated figures, and wrote the manuscript with input from AM; MB, contributed to experiments and performed FACs analysis; PC, contributed to gene expression experiments; LV, MM, helped for resources and revised the manuscript; GBV, contributed to the conception of the project; AM, contributed to the conception and development of the project, data interpretation and revision of the manuscript. All authors have read and agreed to the published version of the manuscript.

Conflict of interest: The authors declare that they have no competing interests, and all authors confirm accuracy.

Availability of data and materials: The data used to support the findings of this study are available from the corresponding author upon request. 


\section{Introduction}

The proper establishment of the gonadotropin-releasing hormone $(\mathrm{GnRH})$ system is essential for the regulation of the reproductive competence. During ontogenesis, GnRH-secreting neurons originate from progenitors located in the olfactory placode and migrate along the route of the olfactory nerves to the hypothalamus where they complete their maturation. ${ }^{1} \mathrm{GnRH}$ neurons remain quiescent until puberty when under permissive signals start to release, in a pulsatile manner, the GnRH peptide regulating sex hormone production and gametogenesis. ${ }^{2}$ Hence, failure of any step of this process may lead to alteration of sex maturation and reproduction.

Research from the past 20 years have documented that some environmental contaminants act as endocrine disruptors interfering with the reproductive system, especially when the exposure occurs during critical developmental periods, such as fetal and perinatal life. ${ }^{3,4}$ Benzo[a]pyrene $(\mathrm{BaP})$ is a widespread persistent organic pollutant ${ }^{5}$ belonging to the endocrine disrupting compounds (EDCs) family. ${ }^{6}$ Thanks to its lipophilic properties, BaP can easily cross the placenta ${ }^{7}$ and acts on fetal development in utero. Increasing evidence, using animal and in vitro models, has shown that several EDCs can alter the neuroendocrine control of reproduction, ${ }^{8}$ but the role of $\mathrm{BaP}$ in affecting maturation of the central $\mathrm{GnRH}$ system in humans remains to be fully explored.

In this study, we examined the effects of $\mathrm{BaP}$ on the survival and maturation of human fetal GnRH secreting neuroblasts representative of developing neurons (FNCB4). ${ }^{9-11}$

\section{Materials and Methods}

\section{Cell culture and reagents}

FNCB4 was previously established, cloned, and propagated in vitro from human fetal olfactory epithelium, ${ }^{9}$ and characterized as GnRH secreting neuroblasts. ${ }^{9-11}$ Cells, cryogenically preserved, were cultured at $37^{\circ} \mathrm{C}$ in $5 \% \mathrm{CO}_{2}$ atmosphere in Coon's modified Ham F-12 medium (Sigma-Aldrich Corp., St. Louis, MO, USA) supplemented with $10 \%$ fetal bovine serum (Hyclone, Logan, UT, USA). BaP was dissolved in dimethylsulfoxide (DMSO; both Sigma-Aldrich) and used at $10 \mu \mathrm{M}$ as most commonly chosen concentration for in vitro toxicity studies. ${ }^{12,13}$ Endothelin 1 (ET1) was obtained from NovaBiochem (Laufelfingen, Switzerland). Cell viability was determined by MTT assay (Sigma-Aldrich), as previously described. ${ }^{14}$ The immunocytochemistry was performed as previously described, ${ }^{15}$ using rabbit anti-GnRH1 polyclonal antibody (1:100; Abcam, Cambridge, UK) and Alexa Fluor 488-conjugated as secondary antibody (1:200; Molecular Probes, Eugene, OR, USA). AlexaFluor 488-conjugated phalloidin (Molecular Probes) was used for cytoskeletal F-actin detection. Nuclei were counterstained with DAPI (Molecular Probes). Images were collected using a Nikon Microphot-FXA microscope (Nikon, Tokyo, Japan). Cells with a motile phenotype were identified by the presence of cytoskeletal remodeling including elongated cell bodies, filopodia and lamellipodia and were expressed as percentage of total cells, as counted in ten fields from two separate experiments.
A

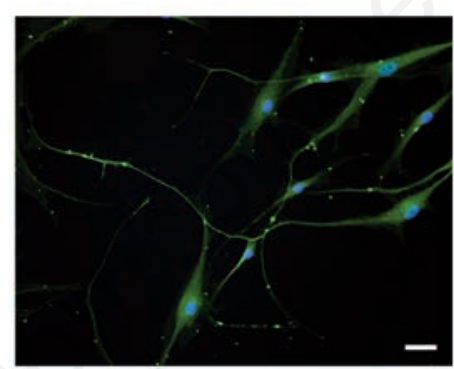

C

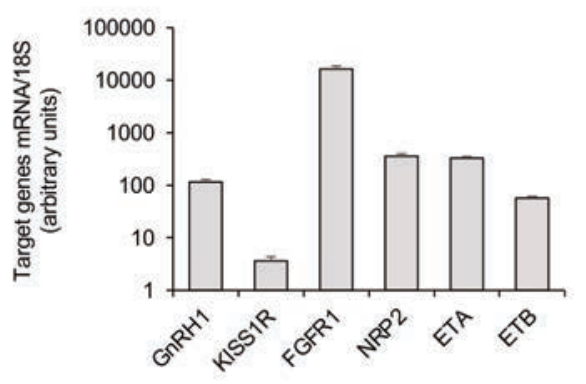

B

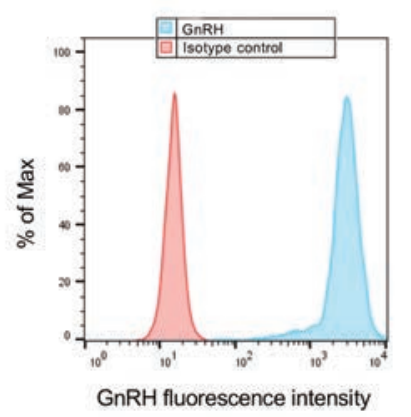

D

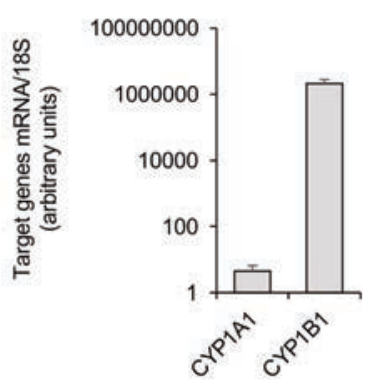

Figure 1. Phenotypic characterization and gene expression profile of FNCB4 cells. A) Representative image of cells expressing GnRH (green) as evaluated by immunofluorescence analysis; DAPI counterstained nuclei; scale bar: $50 \mu \mathrm{m}$. B) Representative overlaid histogram of GnRH protein expression (light blue peak) with its isotype control (negative control; pink peak), as detected in FNCB4 cells by flow cytometric analysis. (C-D) Relative mRNA expression by qRT-PCR analysis of target genes normalized over 18S ribosomal RNA subunit, taken as the housekeeping gene, and reported as mean \pm SEM $(n=9)$. 


\section{Flow cytometry}

As already reported, ${ }^{16}$ after fixation and permeabilization, cells were incubated with anti-GnRH1 (1:100; Abcam) primary antibody. Alexa Fluor 488 goat anti-rabbit IgG (1:200; Molecular Probes) was used as secondary antibody. Stained cells were analyzed on a FACSCanto II flow cytometer (Becton-Dickinson, San Jose, CA, USA) and analyzed with FloJo software (Ashland, OR, USA).

\section{Quantitative real time RT-PCR (qRT-PCR)}

Isolation of total RNA and cDNA synthesis were performed using the RNeasy kit (Qiagen, Hilden, Germany) and the iScript ${ }^{\mathrm{TM}}$ cDNA Synthesis Kit (Bio-Rad Laboratories, Hercules, CA, USA) according to the manufacturers' instructions. qRT-PCR was performed as previously described, ${ }^{17}$ using a CFX96 Two-Color RealTime PCR Detection System (Bio-Rad Laboratories). Primers and probes for the target genes were obtained from Life Technologies
(Carlsbad, CA, USA). The 18S ribosomal RNA subunit was used as the housekeeping gene for relative quantitation of the target genes based on the comparative threshold cycle method..$^{18}$

\section{Migration assay}

Cell migration was assessed with a Boyden chamber system (Greiner BioOne, Essen, Germany) with PET translucent $8 \mu \mathrm{m}$ pore size membrane. Migrated cells were fixed, stained with $10 \%$ Giemsa solution in PBS and counted (3 fields for each insert) in blind under an optical microscope (Carl Zeiss S.p.A., Milan, Italy).

\section{Statistical analysis}

Data are expressed as mean \pm standard error of mean (SEM). Student's unpaired $t$-tests or one-way ANOVA followed by Tukey's post-hoc analyses for multiple comparison were performed, as appropriate, to determine statistical significance $(p<0.05)$, by the Statistical Package for the Social Sciences (SPSS Inc., Chicago, IL, USA).
A

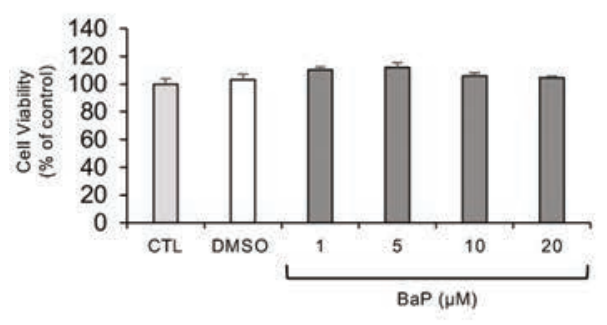

D

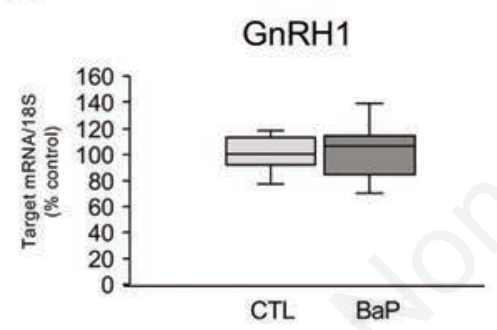

G

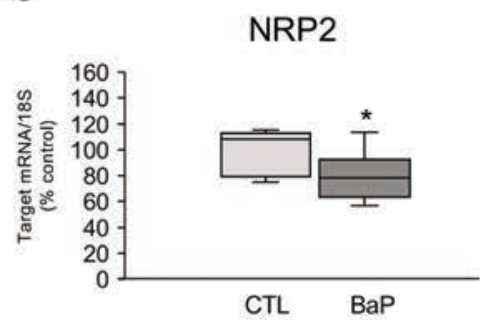

B

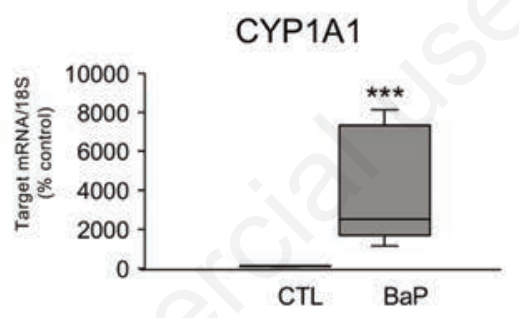

E

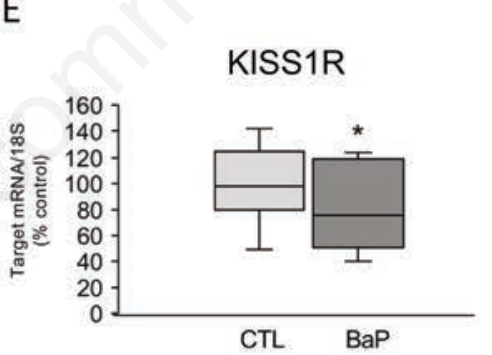

$\mathrm{H}$

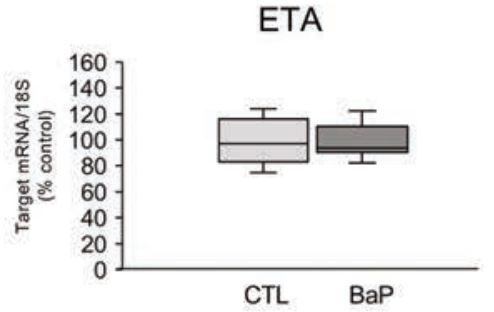

C

\section{CYP1B1}

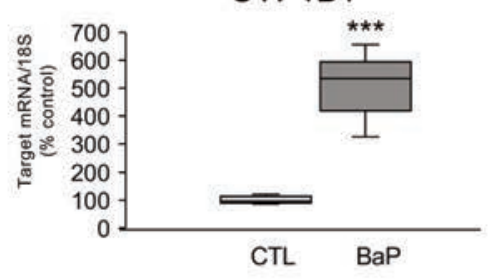

$\mathrm{F}$

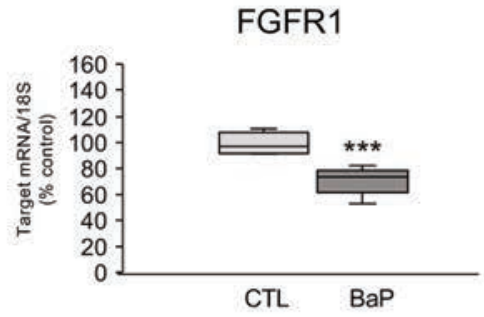

I

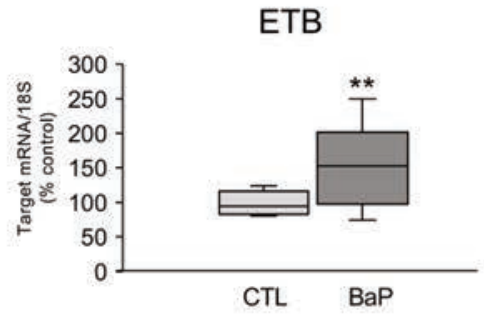

Figure 2. Benzo(a)pyrene effect on FNCB4 cells. A) MTT analysis of FNCB4 cells treated with different concentrations of BaP (1, 5 , $10,20 \mu \mathrm{M}$ ) for $24 \mathrm{~h}$ (dark grey bars); cell viability was expressed as percentage of viable cells over control (untreated cells; CTL; light grey bar), taken as $100 \%$ (mean \pm SEM); vehicle control $(0.04 \%$ DMSO; white bar) was also performed $(\mathrm{n}=4)$. B-I) mRNA expression of target genes in untreated (CTL, light grey box) and BaP-treated (10 $\mu \mathrm{M}$ for $24 \mathrm{~h}$; dark grey box) FNCB4 cells, as detected by qRTPCR. Data are normalized over $18 \mathrm{~S}$ ribosomal RNA subunit, taken as the housekeeping gene, reported as percentage of CTL and displayed as mean \pm SEM. Statistical analysis was performed using unpaired Student's $t$-test; ${ }^{*} \mathbf{p}<0.05 ;{ }^{* *} \mathbf{p}<0.01 ;{ }^{* * *} \mathrm{p}<0.001 ; \mathbf{n}=12$ for CYP1A1 and CYP1B1, $n=9$ for other genes. 


\section{Results}

\section{BaP-induced metabolism in FNCB4}

The identity of FNCB4 as GnRH neuroblasts was confirmed, as already published. ${ }^{11,19,20}$ Cells showed a strong GnRH immunopositivity (Figure $1 \mathrm{~A}, \mathrm{~B}$ ) and the mRNA expression of genes characterizing the GnRH neuroblast phenotype, such as GnRH, KISS1R and genes implicated in GnRH neuron migration (FGFR1, NRP2, ETA and ETB; Figure 1C).

We also verified that FNCB4 expressed CYP1A1 and CYP1B1 mRNAs, the main cytochrome $\mathrm{P} 450$ isoforms responsible for metabolic activation of BaP, with CYP1B1 being the most abundant (Figure 1D).

\section{Effect of BaP on FNCB4 phenotype}

As detected by MTT assay, $24 \mathrm{~h}$ exposure to different concentrations of $\mathrm{BaP}(1,5,10$ and $20 \mu \mathrm{M})$ did not affect FNCB4 cell viability (Figure $2 \mathrm{~A}$ ) and based on these data the subsequent experiments were performed using $10 \mu \mathrm{M} \mathrm{BaP}$. Exposing FNCB4 to BaP
(10 $\mu \mathrm{M}$ for $24 \mathrm{~h}$ ) caused a significant increase in the mRNA level of both CYP1A1 and CYP1B1 (Figure 2 B,C, respectively), as expected..$^{21}$

Concerning the effects on FNCB4 phenotype and function, no significant changes were observed for GnRH1 expression (Figure 2D), whereas KISS1R mRNA was significantly reduced by $\mathrm{BaP}$ exposure (Figure 2E). Interestingly, BaP significantly reduced the mRNA expression of FGFR1 and NRP2 (Figure 2 F,G), while it significantly increased ETB mRNA, as compared to untreated cells (Figure $2 \mathrm{H}, \mathrm{I}$ ).

\section{Effect of BaP on FNCB4 cell migration}

To better investigate the impact of $\mathrm{BaP}$ on FNCB4 migration, cells were exposed to ET1 (100 nM, $6 \mathrm{~h})$. ET1 significantly increased the percentage of migrated cells when compared to untreated cells, whereas BaP exposure $(10 \mu \mathrm{M}, 24 \mathrm{~h})$ significantly prevented this effect (Figure 3A). The evaluation of cellular morphology and cytoskeleton rearrangements indicative of cell movement, confirmed these data. Representative images for immunodetection of F-actin are reported in Figure 3B. Unstimulated cells

A

B
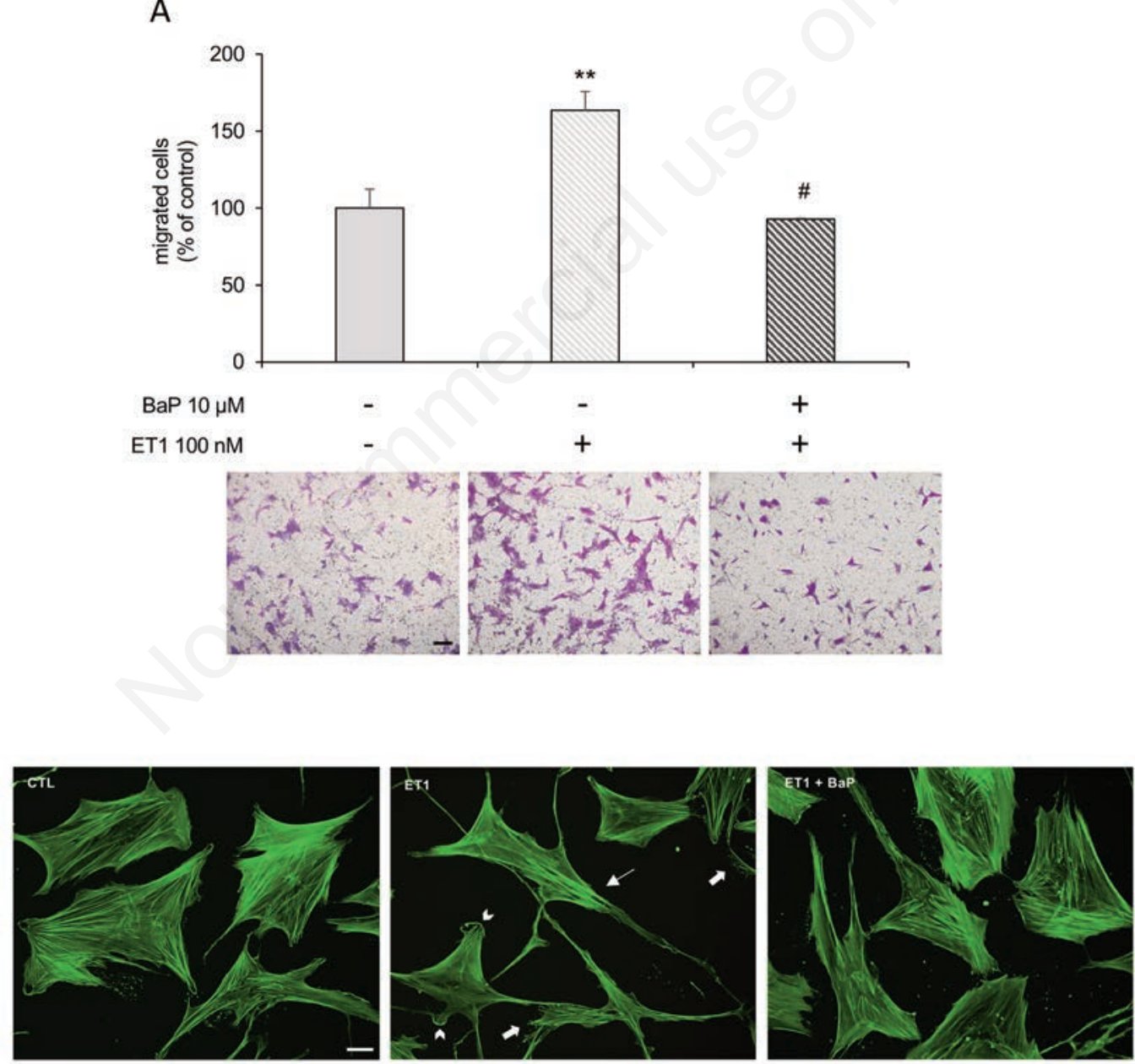

Figure 3. Benzo[a]pyrene alters FNCB4 cell migration. A) Bar graph and representative images showing quantitative analysis of transwell migration assay in FNCB4 cells pre-incubated in presence or absence of $\mathrm{BaP}(10 \mu \mathrm{M}, 24 \mathrm{~h})$ in serum-free medium, and induced to migration with ET1 $(100 \mathrm{nM}, 6 \mathrm{~h})$; migrated cells were counted in 3 different fields for each condition, expressed as percentage of migrated cells over control (untreated cells), taken as $100 \%$ (mean \pm SEM; scale bar $50 \mu \mathrm{m}$ ); statistical analysis was performed using one-way ANOVA ( $\mathrm{p}=\mathbf{0 . 0 0 6})$ followed by Tukey's post-hoc analysis $\left({ }^{* *} \mathrm{p}<0.01\right.$ s untreated cells, \#p<0.01 vs ET1; $\left.\mathrm{n}=9\right)$. B) Representative images of cytoskeleton organization of FNCB4 cells exposed to ET1 (100 nM, $24 \mathrm{~h})$ in presence or absence of BaP (10 $\mu$ M, $24 \mathrm{~h})$ and immunolabeled for F-actin (green) for the detection of microfilaments; arrows, thin arrows, and arrowheads point at cells showing a motile phenotype with elongated cell body, filopodia and lamellipodia, respectively; scale bar: $50 \mu \mathrm{m}$. 
showed a prevalent actin stress fiber network with scarce actin cytoskeletal remodeling detectable in a low percentage of cells (16.8 $\pm 4.1 \%)$. In presence of ET1 (100 nM, 24h), most FNCB4 cells exhibited various actin-based cell deformations compatible with a motile phenotype, including elongated cell bodies, filopodia and lamellipodia (73.6 $\pm 3.4 \% ; \mathrm{p}<0.001$ vs control). The addition of $\mathrm{BaP}$ in co-treatment with ET1 for $24 \mathrm{~h}$ significantly reduced the percentage of motile cells $(23.9 \pm 3.1 \%$; $<0.001$ vs ET1; Figure 3B).

\section{Discussion}

Impaired GnRH neuron migration due to genetic defects is one of the main causes of severe forms of hypogonadotropic hypogonadism $(\mathrm{HH})$ and infertility. Here, we describe for the first time that the migratory properties of human $\mathrm{GnRH}$ neuroblasts may be affected by the exposure to $\mathrm{BaP}$, a widespread environmental pollutant, implicated as EDC in altering gonadal function and consequent fertility. ${ }^{6}$ Our results are consistent with previous findings observed in the mouse exposed to other EDCs, such as bisphenol A. ${ }^{22,23}$ Since the cellular model we used is representative of the early GnRH neuron developmental steps, $, 911,20$ our results strongly suggest that $\mathrm{BaP}$ exposure may interfere with the correct maturation of the hypothalamic neuronal network controlling the reproductive axis. Moreover, FNCB4 are able to metabolize BaP, as they express CYP1A1 and CYP1B1 enzymes, which convert $\mathrm{BaP}$ into bioactive forms.$^{24}$ The strong induction of both isoforms after BaP exposure indicates that FNCB4 cells may be a direct target of the EDC, which therefore affects the gonadal function not only peripherally but also at the brain level. Indeed, a constitutive expression of CYP1A1 has been reported for neuronal and olfactory bulb cells, ${ }^{25,26}$ as well as CYP1B1 is highly expressed in extrahepatic organs ${ }^{27}$ including fetal brain. ${ }^{28}$ Concerning the impact of $\mathrm{BaP}$ on FNCB4 phenotype and function, we found negative effects on the expression of cell migration-related genes, such as FGFR1, NRP2 and ETB, with no GnRH mRNA changes. It is well known that FGFR1 mutations cause genetic disorders associated to $\mathrm{HH}$ with GnRH deficiency and anosmia indicative of GnRH neuron maturation defects. ${ }^{29}$ Moreover, the lack of NRP2 is linked to alteration of the normal migratory process of GnRH neurons. ${ }^{30}$ Accordingly, we demonstrated that $\mathrm{BaP}$ exposure significantly reduced both FGFR1 and NRP2 mRNA, as well as the migratory ability. In contrast, BaP significantly induced ETB expression, which we previously demonstrated as being involved in ET1-induced migration in FNCB4 cells. ${ }^{20}$ ETB induction may be explained by the known ETB-mediated ET1 neuroprotective effects described in the nervous system. . $^{31,32}$

Another interesting finding concerns the observation that $\mathrm{BaP}$ exposure significantly reduced KISS1R mRNA. The kisspeptin/KISS1R system is crucially required as master regulator of GnRH release by mature GnRH neurons within the hypothalamus. ${ }^{33}$ Hence, we can speculate that during the early steps of fetal development this system is mainly implicated in cell migration mechanisms, which may be more sensitive to $\mathrm{BaP}$, rather than in those regulating $\mathrm{GnRH}$ expression. Indeed, kisspeptin has antimetastatic activity ${ }^{34}$ and inhibits ET1-induced FNCB4 migration. ${ }^{35}$ In this context, kisspeptin/KISS1R system could be required for stop signal processes when the neurons reach their destination within the hypothalamus. By reducing KISS1R expression $\mathrm{BaP}$ could also interfere with this important step of GnRH neuron maturation.

In conclusion, our findings contribute to identify a novel scenario by which $\mathrm{BaP}$ exposure may directly induce neuronal injury in the immature brain interfering with the correct maturation of the hypothalamic network regulating reproduction.

\section{Abbreviations}

Benzo[a]pyrene (BaP); endocrine-disrupting compounds (EDCs); endothelin 1 (ET1); gonadotropin-releasing hormone 1 (GnRH1); kisspeptin receptor 1 (KISS1R); fibroblast growth factor receptor 1 (FGFR1); neuropilin 2 (NRP2); endothelin type A receptor (ETA); endothelin type $\mathrm{B}$ receptor (ETB); cytochrome P450 1A1 (CYP1A1); cytochrome P450 1B1 (CYP1B1); hypogonadotropic hypogonadism $(\mathrm{HH})$.

\section{Acknowledgments}

The study was supported by a grant from MIUR (Ministero dell'Università e della Ricerca, Italy; MIUR-PRIN2017, grant no. 2017TK7Z8L_006) to G.G. and A.M.

\section{References}

1. Casoni F, Malone SA, Belle M, Luzzati F, Collier F, Allet C, et al. Development of the neurons controlling fertility in humans: new insights from 3D imaging and transparent fetal brains. Development 2016;143:3969-81.

2. Sisk CL, Foster DL. The neural basis of puberty and adolescence. Nat Neurosci 2004;7:1040-7.

3. Frye C, Bo E, Calamandrei G, Calzà L, Dessì-Fulgheri F, Fernández M, et al. Endocrine disrupters: A review of some sources, effects, and mechanisms of actions on behaviour and neuroendocrine systems: EDCs-sources, effects \& mechanisms. J Neuroendocrinol 2012;24:144-59.

4. Street M, Angelini S, Bernasconi S, Burgio E, Cassio A, Catellani C, et al. Current Knowledge on endocrine disrupting chemicals (EDCs) from animal biology to humans, from pregnancy to adulthood: Highlights from a National Italian Meeting. Int J Mol Sci 2018;19:1647.

5. Guerreiro CBB, Horálek J, de Leeuw F, Couvidat F. Benzo(a)pyrene in Europe: Ambient air concentrations, population exposure and health effects. Environ Pollut 2016;214:657-67.

6. Plunk EC, Richards SM. Endocrine-disrupting air pollutants and their effects on the hypothalamus-pituitary-gonadal axis. Int J Mol Sci 2020;21:9191.

7. McCabe DP, Flynn EJ. Deposition of low dose benzo(a)pyrene into fetal tissue: Influence of protein binding. Teratology 1990;41:85-95.

8. Lopez-Rodriguez D, Franssen D, Bakker J, Lomniczi A, Parent A-S. Cellular and molecular features of EDC exposure: consequences for the GnRH network. Nat Rev Endocrinol 2021; 17:83-96.

9. Vannelli G, Ensoli F, Zonefrati R, Kubota Y, Arcangeli A, Becchetti A, et al. Neuroblast long-term cell cultures from human fetal olfactory epithelium respond to odors. J Neurosci 1995;15:4382-94.

10. Romanelli RG, Barni T, Maggi M, Luconi M, Failli P, Pezzatini A, et al. Expression and function of gonadotropinreleasing hormone $(\mathrm{GnRH})$ receptor in human olfactory GnRH-secreting neurons: an autocrine GnRH loop underlies neuronal migration. J Biol Chem 2004;279:117-26.

11. Maggi M, Barni T, Fantoni G, Mancina R, Pupilli C, Luconi $\mathrm{M}$, et al. Expression and biological effects of endothelin-1 in human gonadotropin-releasing hormone-secreting neurons. J Clin Endocrinol Metab 2000;85:8.

12. Sarma SN, Blais JM, Chan HM. Neurotoxicity of alkylated 
polycyclic aromatic compounds in human neuroblastoma cells. J Toxicol Environ Health A 2017;80:285-300.

13. Slotkin TA, Skavicus S, Card J, Giulio RTD, Seidler FJ. In vitro models reveal differences in the developmental neurotoxicity of an environmental polycylic aromatic hydrocarbon mixture compared to benzo[a]pyrene: Neuronotypic PC12 Cells and embryonic neural stem cells. Toxicology 2017;377:49-56.

14. Sarchielli E, Morelli A, Guarnieri G, Iorizzi M, Sgambati E. Neuroprotective effects of quercetin 4'-O- $\beta$-d-diglucoside on human striatal precursor cells in nutrient deprivation condition. Acta Histochem 2018;120:122-8.

15. Guarnieri G, Sarchielli E, Comeglio P, Herrera-Puerta E, Piaceri I, Nacmias B, et al. Tumor necrosis factor $\alpha$ influences phenotypic plasticity and promotes epigenetic changes in human basal forebrain cholinergic neuroblasts. Int J Mol Sci 2020;21:6128.

16. Sarchielli E, Guarnieri G, Idrizaj E, Squecco R, Mello T, Comeglio $\mathrm{P}$, et al. The $\mathrm{G}$ protein-coupled oestrogen receptor, GPER1, mediates direct anti-inflammatory effects of oestrogens in human cholinergic neurones from the nucleus basalis of Meynert. J Neuroendocrinol 2020;32:e12837.

17. Sarchielli E, Comeglio P, Squecco R, Ballerini L, Mello T, Guarnieri G, et al. Tumor necrosis factor $\alpha$ impairs kisspeptin signaling in human gonadotropin-releasing hormone primary neurons. J Clin Endocrinol Metab 2017;102:45-56.

18. Livak KJ, Schmittgen TD. Analysis of relative gene expression data using real-time quantitative PCR and the $2-\Delta \Delta C T$ method. Methods 2001;25:402-8.

19. Morelli A, Comeglio P, Sarchielli E, Cellai I, Vignozzi L, Vannelli GB, et al. Negative effects of high glucose exposure in human gonadotropin-releasing hormone neurons. Int J Endocrinol 2013;2013:1-8.

20. Romanelli RG, Barni T, Maggi M, Luconi M, Failli P, Pezzatini A, et al. Role of endothelin-1 in the migration of human olfactory gonadotropin-releasing hormone-secreting neuroblasts. Endocrinology 2005;146:4321-30.

21. Gelboin HV. Benzo[alpha]pyrene metabolism, activation and carcinogenesis: role and regulation of mixed-function oxidases and related enzymes. Physiol Rev 1980;60:1107-66.

22. Bai Y, Chang F, Zhou R, Jin P-P, Matsumoto H, Sokabe M, et al. Increase of anteroventral periventricular kisspeptin neurons and generation of E2-induced LH-surge system in male rats exposed perinatally to environmental dose of bisphenol-A. Endocrinology 2011;152:1562-71.

23. Pillon D, Cadiou V, Angulo L, Duittoz AH. Maternal exposure to 17-alpha-ethinylestradiol alters embryonic development of GnRH-1 neurons in mouse. Brain Res 2012;1433:29-37.

24. Uppstad H, Øvrebø S, Haugen A, Mollerup S. Importance of CYP1A1 and CYP1B1 in bioactivation of benzo[a]pyrene in human lung cell lines. Toxicol Lett 2010;192:221-8.

25. Kuban W, Daniel WA. Cytochrome P450 expression and regulation in the brain. Drug Metab Rev 2021;53:1-29.

26. Morse DC, Stein AP, Thomas PE, Lowndes HE. Distribution and induction of cytochrome P450 1A1 and 1A2 in rat brain. Toxicol ApplPharmacol 1998;152:232-9.

27. Rieder CR, Ramsden DB, Williams AC. Cytochrome P450 1B1 mRNA in the human central nervous system. Mol Pathol 1998;51:138-42.

28. Hakkola J. Expression of CYP1B1 in human adult and fetal tissues and differential inducibility of CYP1B1 and CYP1A1 by Ah receptor ligands in human placenta and cultured cells. Carcinogenesis 1997;18:391-7.

29. Pitteloud N, Meysing A, Quinton R, Acierno JS, Dwyer AA, Plummer L, et al. Mutations in fibroblast growth factor receptor 1 cause Kallmann syndrome with a wide spectrum of reproductive phenotypes. Mol Cell Endocrinol 2006;254-255:60-9.

30. Cariboni A, Hickok J, Rakic S, Andrews W, Maggi R, Tischkau S, et al. Neuropilins and their ligands are important in the migration of gonadotropin-releasing hormone neurons. $\mathrm{J}$ Neurosci 2007;27:2387-95.

31. Vidovic M, Chen M-M, Lu Q-Y, Kalloniatis KF, Martin BM, Tan AHY, et al. Deficiency in endothelin receptor B reduces proliferation of neuronal progenitors and increases apoptosis in postnatal rat cerebellum. Cell Mol Neurobiol 2008;28:112938.

32. Ehrenreich H, Nau R, Dembowski C, Hasselblatt M, Barth M, Hahn A, et al. Endothelin B receptor deficiency is associated with an increased rate of neuronal apoptosis in the dentate gyrus. Neuroscience 1999;95:993-1001.

33. Clarke H, Dhillo WS, Jayasena CN. Comprehensive review on kisspeptin and its role in reproductive disorders. Endocrinol Metab 2015;30:124.

34. Lee J-H, Welch DR. Suppression of metastasis in human breast carcinoma MDA-MB-435 cells after transfection with the metastasis suppressor gene, KiSS-i. Cancer Res 1997;57:23847.

35. Morelli A, Marini M, Mancina R, Luconi M, Vignozzi L, Fibbi B, et al. Sex steroids and leptin regulate the "first kiss" (KiSS 1/G-protein-coupled receptor 54 system) in human gonadotropin-releasing-hormone-secreting neuroblasts. J Sex Med 2008;5:1097-113.

\footnotetext{
Received for publication: 31 May 2021. Accepted for publication: 27 July 2021.

This work is licensed under a Creative Commons Attribution-NonCommercial 4.0 International License (CC BY-NC 4.0).

CC Copyright: the Author(s), 2021

Licensee PAGEPress, Italy

European Journal of Histochemistry 2021; 65(s1):3282

doi:10.4081/ejh.2021.3282
} 